\title{
The Development of a Simulated Sediment Dosing Apparatus for Deposition Research in Wastewater Collection Systems
}

\author{
David Campbell1, Sean Mushin'2, Craig Saunders ${ }^{3}$ \\ ${ }^{1}$ Water Academy, Heriot Watt University, Riccarton, Scotland \\ ${ }^{2}$ Heriot Watt University, Riccarton, Scotland \\ ${ }^{3}$ School of the Built Environment, Heriot Watt University, Riccarton, Scotland \\ Email: d.p.campbell@hw.ac.uk, sm830@hw.ac.uk,cs172@hw.ac.uk
}

How to cite this paper: Campbell, D. Mushin, S. and Saunders, C. (2018) The Development of a Simulated Sediment Dosing Apparatus for Deposition Research in Wastewater Collection Systems. Journal of Water Resource and Protection, 10, 493-506.

https://doi.org/10.4236/jwarp.2018.105026

Received: January 12, 2018

Accepted: May 14, 2018

Published: May 17, 2018

Copyright $(9) 2018$ by authors and Scientific Research Publishing Inc. This work is licensed under the Creative Commons Attribution International License (CC BY 4.0).

http://creativecommons.org/licenses/by/4.0/

\begin{abstract}
Water conservation initiatives promote installation of water efficient and low-flow appliances in waste water collection systems. This has resulted in lower flow rates in those systems than the intended design loading, causing solid deposition and sedimentation in some areas. A joint UKWIR/EPSRC CASE grant (14440031) has funded the work described in this paper which investigates sedimentation and solid deposition in building drainage system pipes. The purpose of this paper is to detail the design, calibration and operation of a sediment dosing apparatus to simulate sedimentation rates and explore possible solutions to this issue with a full scale laboratory model based on real site data. The methodology adopted is an experimental approach, where tests have been conducted on the sediment dosing apparatus based on calculations and observations to determine an appropriate sediment dosing regime representative of typical systems. Further tests were conducted with the addition of everyday household products to investigate their effects on sedimentation. The results indicated that a suitable dosing rate was approximately $12 \%$ weight-to-volume (w/v) of a fine sand with a known particle size distribution, diluted 1:5 in a clean water base flow. It was also shown that the addition of the household products added to the problem of sedimentation within drainage systems. The results give excellent correlation to real site data, with deposition depth and distribution comparable to measured site data to within $10 \%$. The deposition was achieved within three hours, which approximated six weeks deposition in the live site used in the study. This straightforward investigation details the design, construction and testing of a device to cause accelerated sedimentation in a full scale model of a building drainage system. This is the first step in the process of updating research underpinning
\end{abstract}


our understanding of the behaviour of these systems under conditions of low flow rates caused by water conservation, sedimentation, and the use of common household additives. It will be used to improve simulation of water flow and solid transport in sediment-laden systems. Specifically, the results will be used to determine refinements required to a specific drainage simulation model (DRAINET), which currently has an unquantified sedimentation component. This work is part of a larger body of current research funded by two joint EPSRK/UKWIR grants.

\section{Keywords}

Water Conservation, Deposition, Modelling, Computer Simulation, Empirical Model, Site Sampling

\section{Introduction and Aim}

The aim of the work reported in this paper is to design and test a simulated sediment delivery system suitable for conducting an empirical analysis of water flow and drain-line carry (of simulated solids) in a full-sized $15 \mathrm{~m}$ physical laboratory model of a drainage system collection pipe. The system will also provide the foundation for extending the capabilities of a mathematical computer-based simulation model, such as DRAINET.

In most building drainage collection systems, sedimentation blockages occur along the bottom section of pipes. This blockage also results in the pipe cross sectional area being reduced and the profile altered: i.e. it is no longer circular. These issues can have a larger impact than simply just reducing the diameter.

As sediment depth increases, the cross-sectional area left for water flow reduces. If the diameter was to be uniformly reduced, say from $100 \mathrm{~mm}$ to $75 \mathrm{~mm}$, there would actually be a benefit on solid carrying capacity as the flow velocity would increase. For applications in building services, this produces a more effective waste transport system although the practice for decades has been to ignore this. Since the cross sectional area reduction happens from the bottom of the pipe upwards though, a much lower rate of discharge through the pipe occurs, which encourages settlement of the carried load. This arises because the flow is distributed evenly across the (now) flat pipe bottom, which also now has greater roughness.

Sedimentation is not only known to have adverse effects on the hydraulic performance of the system but also on the environment. Not only can sediment particles enter the system via flooding, it can also enter during maintenance carried out by the utility providers through re-plumbing and excavation works. It can therefore be said that it is inevitable that the network cannot be fully protected from the threats that come with sedimentation.

Sediment has two crucial effects on the performance of sewage systems: sediment deposits can significantly lower the flow capacity by decreasing the 
cross-sectional area and increasing the hydraulic resistance; and pollutants from foul sewage and industrial effluents attach to inorganic particles, thus the transport of pollutants through a system is directly linked to the movement of sediment [1] [2]. These factors are beyond the scope of the current investigation.

The majority of natural sediments which occur in water supplies are rock, sand, soil and other organic matters, principally oils from cooking. In some regions, the water supply also contains various salts such as iron, calcium and magnesium. In the UK, where there is frequent rainfall and moderate temperatures, a large proportion of these sediments are transported via waterborne methods including natural and man-made water networks.

In most building drainage collection systems, sedimentation blockages occur along the bottom section of pipes. This blockage also results in the pipe cross sectional area being reduced and the profile altered: i.e. it is no longer circular. These issues can have a larger impact than simply just reducing the diameter.

As sediment depth increases, the cross-sectional area left for water flow reduces. If the diameter was to be uniformly reduced, say from $100 \mathrm{~mm}$ to $75 \mathrm{~mm}$, there would actually be a benefit on solid carrying capacity as the flow velocity would increase. For applications in building services, this produces a more effective waste transport system although the practice for decades has been to ignore this. Since the cross sectional area reduction happens from the bottom of the pipe upwards though, a much lower rate of discharge through the pipe occurs, which encourages settlement of the carried load. This arises because the flow is distributed evenly across the (now) flat pipe bottom, which also now has greater roughness.

Sedimentation is not only known to have adverse effects on the hydraulic performance of the system but also on the environment. Not only can sediment particles enter the system via flooding, it can also enter during maintenance carried out by the utility providers through re-plumbing and excavation works. It can therefore be said that it is inevitable that the network cannot be fully protected from the threats that come with sedimentation.

Sediment has two crucial effects on the performance of sewage systems: sediment deposits can significantly lower the flow capacity by decreasing the cross-sectional area an increasing the hydraulic resistance; and pollutants from foul sewage and industrial effluents attach to inorganic particles therefore the transport of pollutants through a system is directly linked to the movement of sediment [1] [2]. These factors are beyond the scope of the current investigation.

The Hazen-Williams equation is used to represent the relationship between the physical properties of a pipe, the flow of water and the pressure drop caused by friction:

$$
H_{l}=10.67 * q^{1.85} / \frac{C^{1.85}}{d_{h}^{4.8655}}
$$

where: $H_{l}=$ Friction loss as metres of water per meter of pipe, $C=$ Hazen-Williams Coefficient, $q=$ flow in $\mathrm{m}^{3} \mathrm{~s}^{-1}, d=$ internal pipe diameter in $\mathrm{mm}$. 
The Hazen-Williams Coefficient ( $C$ ) varies from 60 for 40 -year old cast iron pipe to 150 for new plastic pipe. It can be said that the higher the Hazen-Williams Coefficient, the smoother the pipe. Low coefficients represent a higher level of roughness within pipes which would subsequently result in reduced velocities and head losses.

An object experiences a frictional force as is rises or falls through a liquid. As settling particles are being investigated in this case, Newton's resistance law is no longer valid due to the particles and resistance being too small. Instead Stokes' law can be used to calculate the frictional losses associated with settling particles.

Stokes' Law shows that frictional drag is directly proportional to the weight of the particle [3]. It assumes that the particles are spherical and the flow is laminar, taking into account the particle radius, liquid viscosity and fall velocity. This can be used to determine the settling velocity and time of the sediment particles. However, since calculation of sedimentation was beyond the scope of this investigation, it has been replaced by simple empirical observation at this stage.

When the sediment within pipes deposits, the cross-sectional area is reduced which restricts flow and increases the velocity of flow and head loss. Issues become apparent when the sediment is $10 \%$ of the overall cross-sectional area, if it is $2 \%$ (for example) the issues are relatively small. Sediment creates ripples and dunes within the pipe which increases resistance and bed roughness:

$$
k_{b}=5.62 R^{0.61} d_{50}^{0.39}
$$

where: $R=$ hydraulic radius $(\mathrm{m}) ; d=$ sediment particle size larger than $50 \%$ of all particles in the bed $(\mathrm{m})$.

Under the given conditions, a 5\% depth of deposited sediment with dunes could reduce the pipe-full capacity by $10 \%-20 \%$, with higher velocities these dunes reduce in size under the bed and becomes flatter with lower roughness [4].

Low water use appliances are defined as "water using devices that minimise the amount of water required to perform their specific task" [5]. The difference in volume and flow rates between convectional appliances and low water use appliances is of current interest to water saving initiative drivers, such as Water Wise [6], and is the reason behind the commissioning of the work which led to this paper [7] [8] [9]. The importance of water conservation and its impact on solid transport [10] has been investigated and the effect was measure able even at the early stages of water conservation [11], although manageable with thoughtful engineering design [12] [13].

The Construction Industry Research and Information Association (CIRIA) developed a method which enabled self-cleansing velocities to be specified which represented a number of factors including pipe size, flow depth, pipe roughness, sediment size and type and concentrations. Two factors which are fundamental to this method are to ensure each pipe is individually designed with its own self-cleansing velocity and that some deposition is acceptable. Self-cleansing has been defined by CIRIA as "An efficient self-cleansing sewer is one having a 
sediment-transporting capacity that is sufficient to maintain a balance between the amounts of deposition and erosion, with a time-averaged depth of sediment deposit that minimises the combined costs of construction, operation and maintenance" [14].

In the UK all new sewers and rising mains are designed to be "self-cleansing", where minimum gradients and flow velocities are specified which intended to prevent the build-up of large amounts of sedimentation [2]. The National Build Standards for Design and Construction of new gravity foul sewers and lateral drains discusses the factors to be considered when designing a self-cleaning system, requiring a flow velocity of $0.75 \mathrm{~m} / \mathrm{s}$ and a slope of less than 1:80 for practical building services applications [15]. This was further investigated [16] laying the foundations for a simulation technique later developed by the author.

Simply by depositing material in a pipe, the flow velocity term at least will be challenged as the flow is no longer concentrated in a channel but distributed over the upper flat surface of the sediment. It is inevitable that sediment will deposit during periods of low flow, therefore it is essential to ensure self-cleansing conditions can occur frequently enough to prevent the sedimentation from solidifying [2]. The installation of low use appliances has been increasing, meaning the guidelines on how to create self-cleansing conditions within sewers are likely to change in the future.

Pipe sizing design recommendations are given in BS EN 805:2000_-"Water supply-Requirements for systems and components outside buildings" [17] and BS 6700:2006- "Design, installation, testing and maintenances of services supplying water for domestic use within buildings and their curtilages-Specification" [18]. For both documents pipe size is chosen depending on the maximum design flow rate: BS 6700 offers the possibility of choosing a pipe diameter which meets the design parameters of flow, maximum water velocity and permissible head loss.

If flow velocities decrease, there will be a net reduction in the amount of sediment held in suspension. There is a chance that the material accumulated at the bed will continue to be transported, however if flow velocities are below a certain level the sediment may deposit into the bed. If the flow velocities drop even further, the transportation of sediment will stop completely which can result in blockages [19]. Solid transport in established drainage flows was characterised [20] and a mathematical description obtained which showed that transported solids would interact with the flow in the system, and that this interaction could be simulated mathematically, embodied in the software DRAINET. This technique requires more work to become applicable to future waste water collection networks by combining established detergency work [21] [22] with the current interest in sedimentation which is amplified by water conservation: hence the work reported in this paper.

\section{Proposed Dosing System}

To lay the foundation for extending the capabilities of DRAINET, a delivery 
system was required in order to conduct an empirical analysis of sedimentation build up. For validation purposes, this was based on site sampling information already at hand. By attending routine and emergency callouts with a "choke team" from Scottish Water, qualitative sediment characterisation and quantitative sediment accretion rates were gathered. It was then possible to design and build a sediment dosing system for empirical laboratory investigations, by using an existing full sized test apparatus of two $100 \mathrm{~mm}$ diameter, 1:80 slope, $15 \mathrm{~m}$ lengths joined by an open collection sump. Each $15 \mathrm{~m}$ run included a $7 \mathrm{~m}$ branch with a swept junction. One $15 \mathrm{~m}$ length and branch was in borosilicate glass; the other was transparent plastic. This facility had been used in the development of the DRAINET simulation model described earlier in this paper. The sediment dosing system was required to deliver a known flow rate of water with adjustable levels of suspended sediment, and to be capable of causing realistic sedimentation accretion in greatly accelerated timescales to facilitate investigation. It was anticipated that a base flow would be established just upstream of the sediment dosing point, and that the sediment stream would be very concentrated, diluted at the insertion point by the base flow.

\section{Detergency}

The dosing system consisted of a large sump tank, a smaller header tank and three circulation pumps with a flow meter and control valves, illustrated schematically in Figure 1.

In Figure 1, the upper tank acts as a collection and mixing vessel, who's water depth is constant. The lower tank is a larger secondary collection and mixing vessel, who's depth can vary. The long central pipe allows free mixing between the tanks. Both tanks have recirculation pumps, continuously agitating the suspended load: the recirculation flow rates are many times larger than the dosing rate. By pumping the water from the lower tank to the upper tank at a rate that is

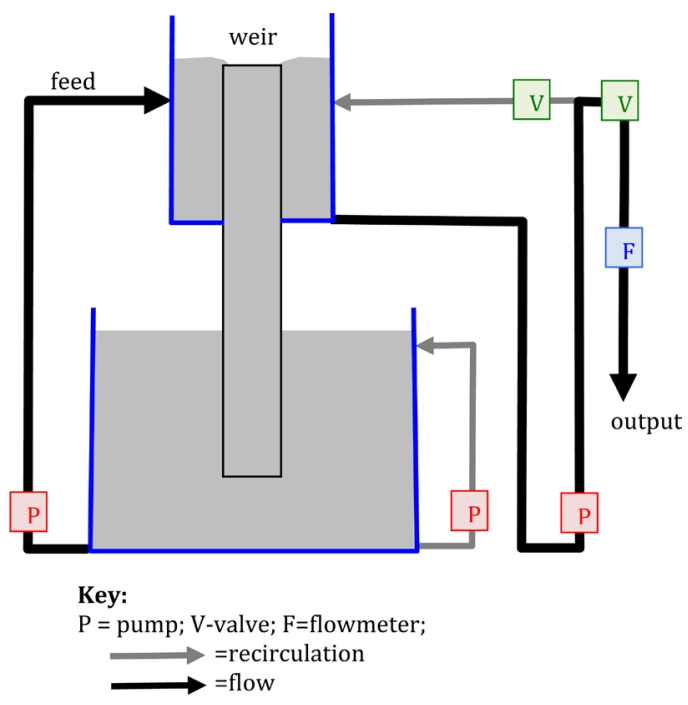

Figure 1. Schematic representation of the sediment dosing system. 
much greater than the dosing rate, the water level in the upper tank remains constant as long as the lower tank contains water. The construction material was $15 \mathrm{~mm}$ Perspex. The sump tank volume was 125 litres and the header tank volume was 45 litres. The purpose of the header tank was to act as a constant supply head for the delivery pump: consequently the header tank had a large weir at the centre which allowed most of the water to flow back into the sump tank, thus maintaining a constant head for the delivery pump regardless of the water depth in the sump tank. Both the sump and header tanks had dedicated recirculation pumps to keep the sediment analogue fully agitated and suspended The flow rate from the unregulated recirculation pumps was approximately $4.5 \mathrm{l} / \mathrm{s}$ which resulted in very turbulent conditions in both tanks, and complete suspension of the sediment analogue. Output control was achieved by a combination of a stop valve and a recirculating valve, returning most of the output back to the sump tank. By dosing the system with the sediment analogue mixture and suitable base flow and running the system until it was exhausted, it could be verified that an insignificant volume of water and sediment analogue remained: well under $0.1 \%$, implying that the recirculation system was effective.

To keep the dosing system small for practical and cost purposes, the sediment analogue would be delivered in concentrated form. To provide the required water volume, a base flow was established by existing pumping facilities immediately upstream of the sediment delivery point.

Using the system was straightforward: the output and recirculation valves were adjusted to give the desired output of a known sediment concentration. The system contained sufficient agitated sediment mixture for around one hour of continuous running, and could be topped up if required by pouring measured quantities of dry sediment analogue and water simultaneously through two large filling chutes. This will have caused a temporary disturbance in the sediment concentration, but this was judged to have a negligible impact because the top-up procedure lasted for around 10 seconds out of around 3700 seconds, and the agitation level of water in both tanks was so high that no visible difference in turbidity could be seen. Since most work was accomplished in 1-hour runs, topping-up was not required.

The aim was to provide a sediment-laden pipe of workable length that included surface roughness over fine and gross scales which was representative of that seen during site surveys. This would provide the basis for revised flow depth measurements and solid transport investigations with which to underpin the DRAINET extension work. It should be remembered that the aim of this work was only to provide a physical test bed for flow and solid transport investigations, and that the nature of real sedimented waste pipes would contain random variability. Nevertheless, the setup outlined in this investigation is much closer to reality than the clean, round-bottom pipes used previously.

Sedimentation deposition dynamics during the deposition period, and deposition profile along the pipework during the deposition period, were both beyond the scope of work of this investigation: only the result of deposition averaged 
along the pipework between 8 equidistant points was considered in a one hour period. The area occluded by sedimentation was calculated from the sediment depth, which was in turn calculated from the arc length (easily obtainable through the glass pipe wall) and basic trigonometry.

\section{Procedure}

\subsection{Overview}

In summary, the process involved applying sediment dosed flow to a base flow for the required time, then measuring the deposition depth over eight points in the pipe. This was repeated with adjustments to the dosing regime as required (with pipe cleaning between each run), until an acceptable deposition profile was achieved over three runs, demonstrating repeatability. Once the correct settings had been established, this process would be repeated with common household cleaning materials.

\subsection{Particle Size Analysis}

To ensure a true replication of real sediment for the laboratory model, samples from test sites provided by Scottish Water "choke teams" were gathered by the author and analysed. The samples were then analysed by microscopy in order to determine the range of different particle sizes present in each sample. Once the results from this were known, an artificial analogue of the sediment was created by using different sizes of sand particles. This was a laborious task involving blending of sifted sand grades in known proportions to achieve the desired distribution. The comparison between the analysed site particle distribution and the replicated sand particle distribution can be seen in Figure 2. This illustrates a relatively close match that would provide a suitable material with which to test the sediment dosing system components.

\subsection{Calibration}

Delivery of sediment-dosed water to the pipe system was simplified by selecting

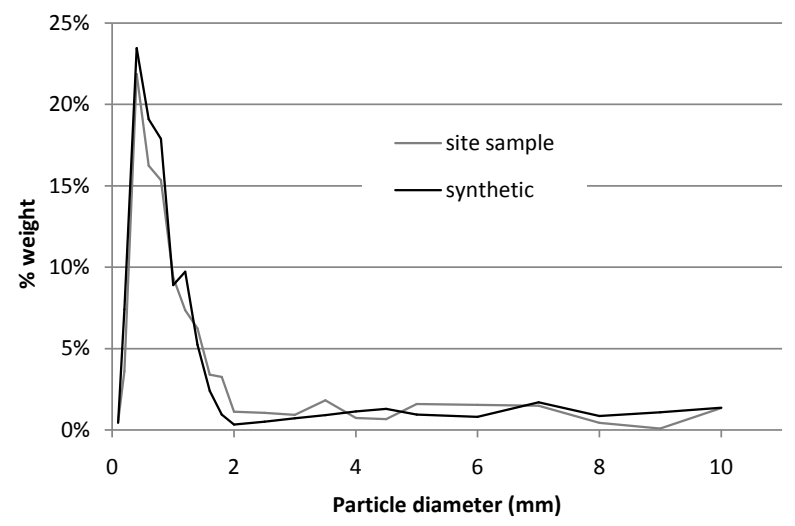

Figure 2. Comparison of particle size distribution in collected site sediment and artificial sediment analogue. 
a particular sediment dosing rate. The simulated sediment particle size distribution is already known. Calibration of the mixed-media digital turbine flow meter for the dosing system was achieved through timing the exhaustion of the system: being cuboids, the volumes were easily marked on the clear Perspex sides. The calibration curve for the output flow meter is shown in Figure 3.

From Figure 3, it can be seen from the correlation coefficient that the pump delivery at the chosen dosing rate was very consistent. The delivery rate was only coarsely controllable which resulted in uneven delivery steps. However this is acceptable as long as enough points can be taken spanning the pump output range. The highly consistent nature of the pump performance can be attributed to two factors:

1) The pump was rated at $3.2 \mathrm{~kW}$ and had an available head of $4.5 \mathrm{~m}$ most of which was by-passed in a recirculation system and was therefore very under-stressed;

2) The constant-head, constant-suspension system arranged at the input to the pump operated as planned resulted in a very consistent load.

In summary, the sediment dosing system can be relied on to deliver a constant and known sediment-dosed water flow to the test system.

The volume of sediment analogue required to build up a $20 \%$ volume reduction in the first $15 \mathrm{~m}$ section of the $100 \mathrm{~mm}$ pipe using $\mathrm{A}=0.5 \mathrm{r}^{2}(\theta-\sin \theta)$ was $65 \mathrm{~kg}$. By dosing over a one hour period, the required delivery rate of sand was $0.0065 \mathrm{~kg} . \mathrm{s}^{-1}$, suspended in $0.068 \mathrm{l} / \mathrm{s}$ of water, then diluted in $0.25 \mathrm{l} / \mathrm{s}$ base flow.

For water additives, a peristaltic pump was used to dispense the liquid. The pump was specifically designed for dosing viscous liquids and had a Vernier adjustment scale for pump stroke.

\subsection{Sedimentation and Deposition Acceleration Rates}

The sedimentation rate chosen was $12 \%$ of sand (measured as $12 \%$ volume in litres of dry sand) per litre of water (i.e. $12 \% \mathrm{w} / \mathrm{v})$. This rate was chosen as it

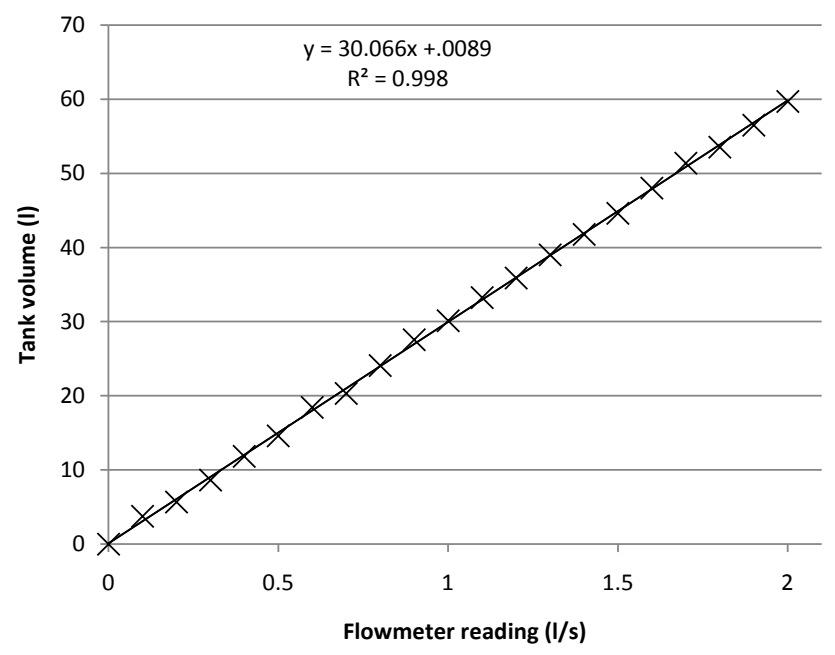

Figure 3. Calibration curve for flowmeter. 
caused sedimentation of the pipework to approximately $20 \%$ of available pipe volume after one hour of continuous running. One hour was a reasonably short working window for a laboratory model, however it achieved approximately 3 months worth of sedimentation based on actual site surveys (information on which was provided by Scottish Water). The deposition acceleration rate was therefore approximately 3 months per hour, or a factor of approximately 1900 .

\subsection{Testing}

\section{Basic Sedimentation Tests.}

Three runs were conducted with a mixture of clean base flow and sediment dosing to establish approximate operating characteristics. A $12 \%$ weight-to-volume $(\mathrm{w} / \mathrm{v})$ ratio was adopted for the sediment delivery, and this would be fed into a base flow of around $0.25 \mathrm{l} / \mathrm{s}$ which is approximately what was seen during site inspections with the "choke teams". This produced an acceptable sedimentation accretion rate that was near the lower end of the sedimentation rate required and allowed good scope for adjustment. For cleaning, water was collected into a settling tank for recovery and reuse of the sediment analogue and the water.

The next stage involved the addition of different household additives to the water with the intention of changing the water chemistry to determine its effect of the deposition of sediment. The pipework was cleaned between each test. This was a lengthy process involving the pumping of 4 tonnes of water while pulling weighted hessian rags through. To maintain known water quality conditions, collection and recirculation of water was not possible with these tests.

The first additive used was soap at a $6 \%$ concentration of neat product, measured as a percentage of the base flow and dosing flow. The author had previously determined that this was the recommended level of soap-based detergent recommended for dishwashing and laundry, although it is common consumer practice to overdose (Campbell \& Macleod, 2000, 2001). This is typically composed of 5\% - 15\% non-ionic surfactants and 5\% anionic surfactants. Fabric conditioner was tested next, representing cationic surfactants and typically at $15 \%$. The final type tested was a mildly caustic surfactant used in dishwashers, which was dosed at the rate of $25 \mathrm{~g}$ of product per $12 \mathrm{l}$ of base flow representing the discharge from a typical dishwasher. These additives all affected the $\mathrm{pH}, \mathrm{eH}$ and viscosity of the water and all affected deposition rates, although a quantitative analysis of these mechanisms was beyond the scope of this investigation.

\section{Results}

Test 1 -plain sediment and clean water base flow.

Figure 4 shows the sedimentation depth results of 3 replicates of clean water and the recommended sediment dose for 1 hour, together with the average sedimentation depth.

Test 2-no additional sediment and clean water base flow.

Figure 5 shows the sedimentation depth after a period of 4 hours of pumping 


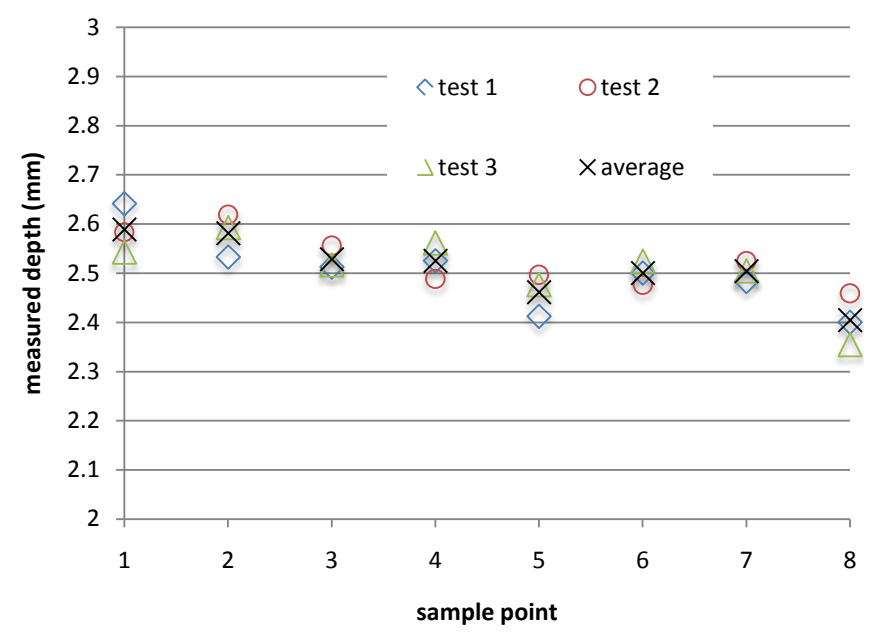

Figure 4. Replicates of three separate sedimentation deposition runs, with average.

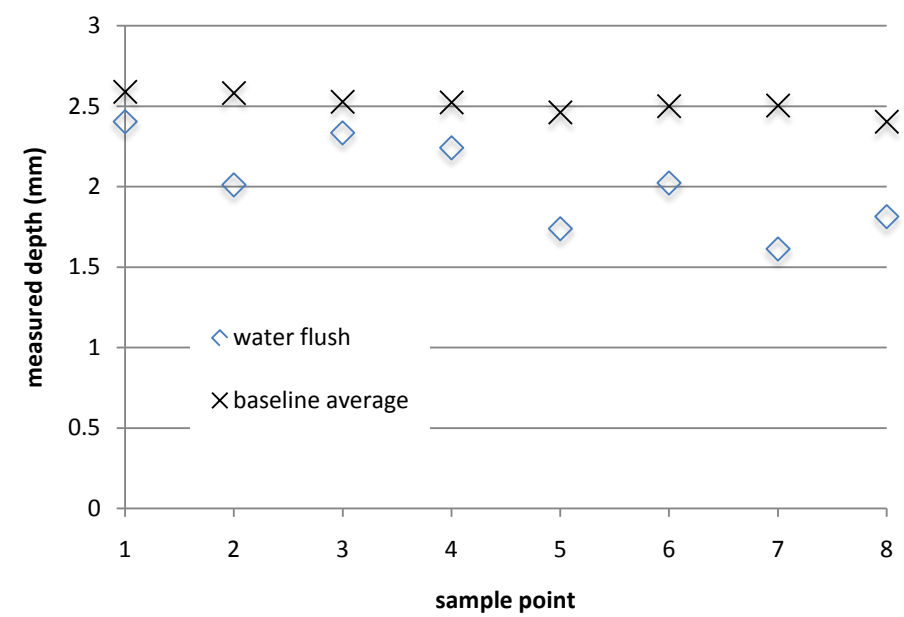

Figure 5. Migration of deposited sediment after four hours flushing with clean water at high flow rate.

through the base flow of clean water on top of the accumulated sediment from test 1 , with no added sediment, together with the average sedimentation depth from test 1 .

Test 3-soap-dosed sediment and clean water base flow.

Figure 6 shows the sedimentation depth results of clean water and the recommended sediment dose with the addition of soap for 1 hour, together with the average sedimentation depth from test 1 .

Test 4-conditioner-dosed sediment and clean water base flow.

Figure 6 shows the sedimentation depth results of clean water and the recommended sediment dose with the addition of conditioner for 1 hour, together with the average sedimentation depth from test 1.

Test 5-dishwasher detergent-dosed sediment and clean water base flow.

Figure 6 shows the sedimentation depth results of clean water and the recommended sediment dose with the addition of dishwater detergent for 1 hour, together with the average sedimentation depth from test 1. 


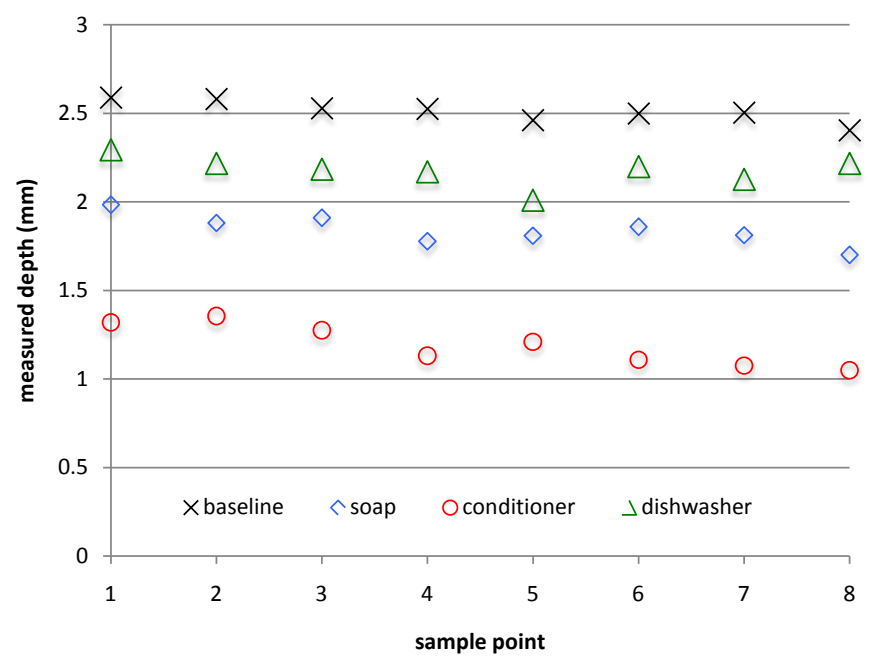

Figure 6. Comparison of sedimentation rates for three different common domestic water additives compared to clean water baseline.

\section{Discussion}

Although an analysis of the mechanisms behind these effects are beyond the scope of this investigation, a quantitative analysis of the tests reveals that there are marked differences in deposition rates and patterns, which will be studied at length in follow-on work. The results also demonstrate that a stable and realistic sedimentation profile is generated which will be an acceptable test bed for DRAINET development.

Test 1 -plain sediment and clean water base flow.

From Figure 4, the three replicates gave a consistent performance with a gradually tailing profile. There were only small surface ripples of the sediment, but these are probably underestimated by the measurement technique of measuring the length of the arc made by the sediment at the measurement points. The ripples were observed to reduce in magnitude close to the pipe wall.

Test 2-no additional sediment and clean water base flow.

From Figure 5, there is a degree of sediment removal taking place, consistent with "nicking" and dune transportation observed in open channel flow. The degree of sediment removal is still quite small, and the base flow of $2.5 \mathrm{l} / \mathrm{s}$ for 4 hours is equivalent to approximately two weeks worth of actual flow of clean water, if applied to the site in question. This is very unlikely to occur in practice. It does indicate though that the deposition of sediment will be acceptable for short term testing of solid transport for the purposes of extending DRAINET.

Test 3-soap-dosed sediment and clean water base flow.

From Figure 6, the addition of soap appears to inhibit deposition by approximately $14 \%$, and increases the slope of the deposition profile.

Test 4-conditioner-dosed sediment and clean water base flow.

From Figure 6, the addition of conditioner appears to inhibit deposition by approximately $45 \%$, and increases the slope of the deposition profile.

Test 5-dishwasher detergent-dosed sediment and clean water base flow. 
From Figure 6, the addition of dishwasher detergent appears to inhibit deposition by approximately $20 \%$, and increases the slope of the deposition profile.

\section{Conclusions}

The sediment dosing system meets the requirements set out in this paper. It can create an acceptable representation of a sedimented pipe, suitable for further refinement of the DRAINET simulation model. While limited in scope, these limitations will not impact on this primary purpose of the system. It is not anticipated that detailed analysis of the modification to sediment deposition caused by household detergents will be undertaken with the apparatus described here. The apparatus may form the starting point for such work, however.

Further development of DRAINET will involve changes to the way that water depth is calculated, and changes to the description of solid transport, deposition and solid-to-solid interaction. These are expected to change significantly as the pipe now has an uneven and flatter bottom, not a round one, and the surface roughness will have changed.

The inclusion of very simplistic assessment of detergent modification to sedimentation could be incorporated into DRAINET. At this stage, and with these very basic results, a realistic approach would be to include a user selectable parameter that could represent detergent type, interactively modifying hydraulic conditions. These investigations will now be able to proceed.

The impact of this work will have bearing on the scientific and engineering communities. Following the detailed work by May [2], there has been relatively little progress in quantifying modern deposition rates in drainage systems with a view to replicating it, and no proposals for a standardised device to use in laboratory situations internationally. The work described in this paper offers a starting point with which to develop international collaboration in the future. Drainage Engineers will now have the ability to replicate a range of deposition types in a laboratory setting and use the results to develop new solutions or refine existing ones. It is anticipated that future developments will include solid transport comparisons and refinements of existing Building Code predictions.

\section{References}

[1] May, R., Brown, P., Hare, G. and Jones, K. (1989) Self-Cleansing Conditions for Sewers Carrying Sediment. Hydraulics Research Ltd., Wallingford, Oxfordshire. http://eprints.hrwallingford.co.uk/1087/1/SR221.pdf

[2] May, R. (1993) Sediment Transport in Pipes and Sewers with Deposited Beds. HR Wallingford, Wallingford, Oxfordshire.

[3] Hodgkins, L. (2016) Stokes' Law and Terminal Velocity. http://www.schoolphysics.co.uk/age16-19/Properties\%20of\%20matter/Viscosity/tex t/Stokes_law/index.html

[4] Coleman, S., et al. (2003) Closed-Conduit Bed-Form Initiation and Development. Journal of Hydraulic Engineering, 129, 12.

[5] Escarameia, M. and Lauchlan, C. (2005) Implications of Site Drainage Systems of 
Reduced Capacity. Environmental Hydraulics and Sustainable Water, 131, 189-211.

[6] UKWIR Technical Report (2018) Flow Modelling of Urban Water Distribution Systems Using Water Conservation Fittings, UKWIR Reference 18/CL/12/3.

[7] UKWIR Technical Report. (2016) Integration of Behavioral Change into Demand Forecasting and Water Efficiency Practices, UKWIR Reference 16/WR/01/15.

[8] Campbell, D.P. (2008) Impacts of Low Water Consumption Fittings in the UK Drainage Infrastructure. CIBW62 International Symposium on Water Supply and Drainage for Buildings, Brussels, 16 September 2008, 104-119.

[9] Campbell, D.P. (2011) Developments in Mathematical Simulation of Fluid Flow in Building Drainage Systems. Building Service Engineering Research \& Technology, 33, 1-11.

[10] McDougall, J. (2003) The Influence of Water Conservation on Drain Sizing for Building Drainage Systems. Building Services Engineering Research and Technology, 24, 229-243. https://doi.org/10.1191/0143624403bt074oa

[11] Wise, A.F.E. (1986) Water, Sanitary and Waste Services for Buildings. 2nd Edition, Mitchel, London.

[12] Swaffield, J.A. and Galowin, L.S. (1992) The Engineered Design of Building Drainage Systems. Ashgate Publishing Limited, England.

[13] Swaffield, J.A. and McDougall, J.A. (2000) Simulation of Building Drainage System Operation under Water Conservation Design Criteria. Building Services Engineering Research and Technology, 21, 45-55.

[14] May, W.P., et al. (1996) Development of Design Methodology for Self-Cleansing Sewers. Water Science \& Technology, 33, 195-205.

https://doi.org/10.1016/0273-1223(96)00387-3

[15] Swaffield, J.A., McDougall, J.A. and Campbell, D.P. (1999) Drainage Flow and Solid Transport in Defective Building Drainage Networks. Building Services Engineering Research and Technology, 20, 73-82.

[16] Gormley, M., Campbell, D.P. and McDougall, J.A. (2004) The Interaction of Solids in Near Horizontal Drainage Pipes. CIBW62 Symposium on Water Supply and Drainage for Buildings, Paris, September 2004, 277-289.

[17] BSI (2000) BS EN 12056-2:2000 Gravity Drainage Systems inside Buildings. BSI, London.

[18] BSI (2008) BS 6700:2006 Design, Installation, Testing and Maintenance of Services Supplying Water for Domestic Use within Buildings and Their Curtilages-Specification. BSI, London.

[19] Butler, D. and Davies, J. (2004) Urban Drainage. 2nd Edition, Spon Press, London.

[20] Campbell, D.P. (2011) Experimental Application of Particle Imaging to Fluid Velocity Analysis in Building Drainage Systems. Building Service Engineering Research \& Technology, 32, 263-275. https://doi.org/10.1177/0143624410396428

[21] Campbell, D.P. and MacLeod, K.A. (2000) Detergency in Drainage-Waste-Ventilation (DWV) Systems. Building Service Engineering Research \& Technology, 21, 35-40.

[22] Campbell, D.P. and MacLeod, K.A. (2001) Detergents in Drainage Systems for Buildings. Water Research, 35, 1086-1092. 